\title{
Conexões
}

Educação Fisica, Esporte e Saúde

DOI 10.20396/conex.v18i0.8659334

Artigo Original

\section{Reflexões sobre a prática interativa na Equoterapia à luz da Praxiologia Motriz}

José Ricardo da Silva Ramos ${ }^{1}$

\section{RESUMO}

Este artigo tem como foco o estudo da Equoterapia dentro da Praxiologia Motriz. Em nossa análise, ressaltamos os fundamentos teóricos e operacionais da Praxiologia Motriz com a tarefa de analisar a Equoterapia da Universidade Federal Rural do Rio de Janeiro (UFRRJ). Nesse sentido, a pesquisa praxiológica realizou-se permeando a práxis da Equoterapia no espaço, tempo, estratégias motrizes, interações, estrutura, normas e na semântica de códigos semiomotrizes, desenvolvida pelos agentes da Equoterapia da UFRRJ. Essa situação motriz desencadeou um olhar praxiológico da ação motriz fundamentada na concepção da sociomotricidade equestre, que nos revelou os principais modelos operatórios de conhecimentos ocultos que foram observados no funcionamento de uma prática terapêutica. Assim, as lentes praxiológicas forjadas por Parlebas (1987, 1999) marcam os modelos operatórios para o desvelamento da estrutura interna de um encontro motor entre humanos e cavalos.

Palavras-chave: Praxiologia Motriz. Equoterapia. Lógica interna.

\footnotetext{
1 Universidade Federal Rural do Rio de Janeiro.
}

\section{Correspondência:}

José Ricardo da Silva Ramos. Universidade Federal Rural do Rio de Janeiro, Instituto de Educação. Antiga Estrada Rio São Paulo Km 47, CEP 23851970, Seropédica, RJ, Email: josericardo63@gmail.com 


\section{Reflections on the interactive practice in equine- assisted therapy in the light of Motor Praxiology}

\section{ABSTRACT}

This article focuses on the study of equine-assisted therapy within Motor Praxiology. In our analysis, we highlighted the theoretical and operational foundations of Motor Praxiology with the task of analyzing in equine-assisted therapy at the Federal Rural University of Rio de Janeiro (UFRRJ). In this way, praxiological research was carried out permeating the praxis of equine-assisted therapy in space, time, motricity, interactions, structure, norms and in the semantics of motricity codes, developed by UFRRJ's equine-assisted therapy professionals. This motor situation initiated a praxiological outlook on making motor based on the concept of sociomotricity, which showed us the main operating models of hidden knowledge that were observed within a therapeutic practice. Thus, the praxiological lenses forged by Parlebas $(1987,1999)$ mark the operative models for the unveiling of the internal structure of a motor encounter between humans and horses.

Keywords: Motor Praxiology. Equine-Assisted Therapy. Internal logic.

\section{Reflexiones sobre la práctica interactiva en Equinoterapia a la luz de la Praxiología Motriz}

\section{RESUMEN}

Este artículo se enfoca en el estudio de la Equinoterapia dentro de la Praxiología Motriz. En nuestro análisis, recalcamos los fundamentos teóricos y operativos de la Praxiología Motriz con la tarea de analizar la Equinoterapia de la Universidad Federal Rural de Río de Janeiro (UFRRJ). En este sentido, se llevó a cabo una investigación praxiológica que permea la praxis de la Equinoterapia en el espacio, tiempo, estrategias motrices, interacciones, estructura, normas y en la semántica de los códigos motrices, desarrollados por los agentes de Equinoterapia de la UFRRJ. Esta situación motriz desencadenó una mirada praxiológica a la acción motriz basada en el concepto de sociomotricidad, que nos reveló los principales modelos operativos de los conocimientos ocultos que se observaron dentro de la práctica terapéutica. Así, las lentes praxiológicas forjadas por Parlebas $(1987,1999)$ marcan los modelos operativos para la revelación de la estructura interna de un encuentro motor entre humanos y caballos.

Palabras Clave: Praxiología motriz. Equinoterapia. Lógica interna. 


\section{INTRODUÇÃO}

A Praxiologia Motriz é considerada uma ciência. Fundada pelo professor Pierre Parlebas, aspira estudar as ações motrizes que emergem em qualquer situação motriz e/ou lúdica. Essas ações surgem como consequência de uma completa trama de relações que se estabelecem entre os participantes de um determinado encontro motor particular (LAGARDERA OTERO; LAVEGA BURGUÉS, 2003). Para Lagardera Otero e Lavega Burgués (2003, p. 69), a lógica interna de um determinado encontro motor e/ou situação motriz elucida que o mesmo(a) é portador(a) de um esquema básico de comportamentos coerentes com a estrutura de cada encontro. Essa estrutura possui um modo de organização interna que segue, invariavelmente uma sequência lógica dentro de um sistema motor.

Entre esses encontros motrizes, um em especial, constituirá o cerne deste estudo: a tarefa de apresentar a radiografia da Equoterapia dentro dos princípios da Praxiologia Motriz.

É importante observar que essas duas concepções são construções históricas e culturais. Há um olhar que, costurado no cotidiano da Equoterapia, nos conduz a um tipo de visão formal que a define como um método terapêutico, reabilitacional e educacional, que conta com a participação do cavalo de forma multidisciplinar no desenvolvimento biopsicossocial da pessoa com necessidades especiais (ANDE, 2013).

De outra forma, apropriada pela concepção praxiológica, tal situação motriz (a Equoterapia) pode ser "descortinada" para a comunidade acadêmica ver outro parecer educativo. Um parecer provocador, no qual anuncia que a mesma possui uma logicidade interna e, ao mesmo tempo, conceitos universais ludomotrizes, operatórios e funcionais que se constituem na materialidade de ações motrizes ${ }^{2}$ entre sujeitos praticantes e agentes equoterápicos (incluindo cavalos).

Um dos assuntos mais prementes da pesquisa praxiológica são os chamados universais ludomotrizes, que são os modelos operatórios de descortinar uma situação motriz ou particularidades presentes em todos os encontros motrizes e lúdicos. Uma das bases da ciência praxiológica é justamente a possibilidade de encontrar princípios ocultos que governam todos os eventos motrizes (PARLEBAS, 1999).

Ou seja, a própria prevalência de um jogo como amarelinha é o seu traço

\footnotetext{
2 Parlebas (1999) assevera que a ação motriz é o processo de realização das condutas motrizes de um ou vários sujeitos atuando dentro de uma situação motriz determinada e que, a mesma, se manifesta por comportamentos observáveis, unidos a um contexto objetivo; comportamentos que se desenvolvem sobre um conjunto amplo de dados subjetivos (emoções, relações, antecipações, decisões, etc.).
} 
universal e definidor da natureza de uma brincadeira motriz, infantil e lúdica. Inclusive, não há dúvida de que se trata de um fato motor com raízes culturais: em algum período do desenvolvimento universal, a brincadeira amarelinha emergiu como função lúdica útil para a interação de sujeitos brincantes. É possível verificar nela os universais ludomotrizes pelas lentes praxiológicas (PARLEBAS, 1996), que refletem os meios explicativos de uma série de aspectos ou parâmetros como espaço, tempo, estratégias motrizes, interações, estrutura, normas e códigos dentro de sua estrutura funcional.

Este outro olhar busca descrever, analisar e compreender os sentidos de sujeitos que constroem um determinado acontecimento motor. São por meio das bases operativas dos universais que procuramos desvendar um encontro equestre, como a Equoterapia desenvolvida na Universidade Federal Rural do Rio de Janeiro (UFRRJ). A nossa suposição é que ela pode contemplar também a nossa capacidade de observar via essas lentes operacionais, trocas interativas e refletir sobre um universo terapêutico, lúdico e motor.

Por isto, pensar em "como" a Equoterapia se articula dentro da ciência da ação motriz (a Praxiologia Motriz) é um bom aprendizado para melhor compreendermos o cotidiano de uma situação particular. Ao experimentar este exercício praxiológico, disseminamos outras referências, que extrapolam o universo restrito da Equoterapia como um mero método formal. Ampliá-la a outra dimensão descritiva, que mostra como sujeitos se expressam dentro de uma estrutura peculiar nos momentos mais diversos desse sistema motor. Isso é fundamental para se compreender outras formas de produção e, como podemos apropriar da logicidade veiculada neste universo.

\section{A REALIDADE PRÁXICA DA EQUOTERAPIA: CAVALOS E HUMANOS EM INTERAÇÃo}

A Equoterapia é forjada de cavalos e humanos interagindo o tempo todo. Eles formam uma equipe que, mutuamente, interagem frente ao desafio de atender as necessidades especiais do sujeito que monta o cavalo (o praticante). 0 desafio está em envolver o praticante com o cavalo. O cavalo, como um ser vivo, é empenhado e treinado para gerar as ações motrizes necessárias para agir sobre quem está montado, com um sentido primordial de atuar, de agir sobre o outro (o praticante) e de cumprir uma tarefa motriz: estimular as dimensões biopsicossociais do praticante.

Uma das ações motrizes do cavalo parte de sua andadura instintiva (o passo). É uma conduta motriz espontânea, a qual é composta do resultado físico, biomecânico do animal, que fornece ações que tornam o cavalo um agente cinesioterapêutico, pois o passo completo do cavalo apresenta ações semelhantes aos do caminhar humano, com deslocamentos multidirecionais oscilatórios que estimulam todo o corpo do sujeito (o praticante) que monta. Nesse sentido, a Praxiologia Motriz entende que esta ação pode ser compreendida como integração 
de significação práxica, dentro de uma realidade práxica, como uma sessão equoterápica. Essa e outras condutas motrizes do cavalo é suscetível de ser analisada dentro de uma determinada situação motriz (RAMOS, 2017).

É significativo salientar, ainda que seja evidente considerar, que é a partir das ações motrizes de agentes equoterápicos (incluindo o animal cavalo) que chegamos à compreensão do funcionamento da Equoterapia como uma situação estruturada, que possui uma lógica interna capaz de representar um sistema de base dentro de seu funcionamento (PARLEBAS, 1999).

Perseverando em compreender o pacto motor do animal e a ação humana, seguramente, Parlebas (1999) descreve minuciosamente como a perspectiva estrutural/sistêmica da Praxiologia Motriz pode fundamentar um elo de colaboração entre humano e cavalo, identificando uma situação motriz em que todos os agentes têm uma meta em comum até o final da atividade equoterápica: a interação motriz essencial, direta, que tem como finalidade desenvolver a dimensão biopsicossocial do praticante, em que, para isso, cavalo e humanos devem se comunicar cooperativamente, atentando para as incertezas do meio externo, sustos ou sobressaltos durante toda uma sessão equoterápica.

Isso só é possível quando as interações, entre cavalo e humanos, são realimentadas por ações cooperativas. Para isso, os agentes estabelecem um pacto acessível, sincronizado de ações motrizes, prenunciando que não pode haver condutas opacas e/ou opositivas que intermedeiem o processo interativo. Nesse ponto, a Equoterapia é um acontecimento dentro de uma rede de interações contínuas, em que a situação que a marca é estritamente cooperativa entre os agentes, previamente planejada/processada por meio da harmonia grupal, com intercâmbio de ações sociomotrizes ${ }^{3}$, em que a culminância será o interesse e cuidado aplicado na execução da tarefa sociomotriz do grupo como um todo.

\section{O MODELO PRAXIOLÓgICO EM QUESTÃo}

A apropriação da rede de papéis (PARLEBAS, 1999), dentro da Equoterapia, pode ser dinamizada por situações que estimulam as ações comportamentais/motrizes de cooperação entre os agentes equoterápicos. Procedendo praxiologicamente, todo o papel se associa a um status motor, que não se define por sujeitos concretos que atuam no campo, mas por suas ações (comportamentais/motrizes e/ou verbais). Elas existem dentro das normas (ou regras) que vão se deliberando na relação intergrupal e nas atribuições de cada sujeito no momento da sessão em curso.

3 Detalhamos que, dentro de uma atividade ou sessão equoterápica, todos os agentes (equoterápicos) possuem um conhecimento da estrutura da prática equoterápica (que é a parte sociomotriz da Equoterapia). A sociomotricidade, para Parlebas (1999), se enquadra na possibilidade de estudar o aspecto interativo do encontro motor, em que os indivíduos atuam um com os outros no espaço/tempo de um fenômeno motor, interatuando corporalmente. 
Essa noção básica de papéis se estabelece em um espectro de propriedades exclusivas na sessão equoterápica. Os papéis se caracterizam em função da norma já estabelecida, a qual define a atribuição de cada agente dentro dessa estrutura. Parlebas (1996) também introduz a questão de contrato ludomotor, avaliando os direitos e deveres de cada sujeito possui no espaço da atividade motriz. O contrato ludomotor é fundamentado em um pacto convencional, por meio do qual os sujeitos de certo evento lúdico/motor/esportivo obedecem à funcionalidade das ações motrizes dentro de normas, regras e firmas tácitas desse evento.

Pode parecer, então, que o sistema e ações motrizes se coincidem. Eles se assemelham quanto ao aspecto estrutural, pois se as ações motrizes devem ser funcionais, o sistema indica quais são os elementos mediadores dessa funcionalidade. Por conseguinte, a investigação praxiológica de uma situação motriz, que se pretenda ser diligente, deve enfocar o exame dos mecanismos subjacentes ao percurso, que vai da invariância (a estrutura) ao grau culminante de variações motrizes observáveis no comportamento motor de cada indivíduo.

O evento motor, que inclui um animal (o cavalo), repercute primordialmente sobre o fazer humano. A cada sessão, os papéis podem mudar nos modos de ver e ler a estrutura sociomotriz da Equoterapia, com exceção do papel do cavalo, que visceralmente gera a ação motriz tridimensional. O papel cabível ao cavalo, ou seja, a sua andadura (o passo), não permite que outro agente exerça o seu papel fundamental. Este papel do cavalo existe em relação à sua proeminência funcional/relacional e à conexão dos outros agentes nesta ação motriz do cavalo na Equoterapia.

Ao mesmo tempo, existem outros papéis, normativamente, em cada espaço/tempo deste evento equestre. A lógica interna destaca outros papéis na Equoterapia, além da maneira motriz de o cavalo se deslocar: o mediador, o praticante, o auxiliar lateral e o auxiliar guia. Na leitura praxiológica, podemos confirmar a função do agente mediador que, especialmente, representa o líder da equipe. Ele busca realizar diversas atividades da terapia equestre, como o planejamento da sessão e intervenção direta nas necessidades especiais de quem está sobre o cavalo (o praticante). Ele dá ordens e emite sinais para o cavalo andar, trotar ou parar, decide sobre as informações e ações motrizes que deverão ser concretizadas pelo praticante e organiza o ambiente em função das vicissitudes educacionais especiais de cada praticante, em particular.

$\mathrm{O}$ agente mediador precisa transformar o ambiente equoterápico em um espaço lúdico, prazeroso e inclusivo. E para isto, ele precisa que sua função motriz se dê no sentido de provocar múltiplas interações com o praticante. Este tem o papel de ser o centro da ação equoterápica como um todo, comumente um sujeito 
com necessidades especiais que deve ajustar sua psicomotricidade 4 às ações motrizes do cavalo. Tal psicomotricidade, por sua vez, assume a dimensão motriz de constantes (re) equilíbrios que o cavalo provoca, o que releva o desejo motor de o praticante buscar os ajustes tônicos constantemente sobre o cavalo.

A ação motriz tridimensional depende exclusivamente do cavalo. É ele que possibilita esta conexão transferencial, que serve para dar significação a esta situação motriz: a Equoterapia. Todavia, o que está em jogo é o trabalho cooperativo: o corpo cavalo/corpo humano na resolução de um problema motor, com esse jogo de forças, adaptações e ajustes; vai se encarnando o jogo das relações entre o cavalo e o humano, ou seja, uma sociomotricidade concretamente identificável. Fugir desse vínculo para uma produção instável representa a negatividade na cadeia de significação sociomotriz, e sugere um ato perigoso ou até mesmo trágico.

Nesta situação motriz peculiar, podemos asseverar que toda a equipe se coloca como parceira do praticante, em que todos os agentes trabalham dentro de uma rede estável e invariável, cooperativamente a favor do desejo de o praticante adotar o gosto pelo ambiente durante toda a sessão. Ele (o praticante) é um sujeito exposto a situações motrizes vulneráveis, como uma deficiência (física, sensorial, motriz, etc.), um transtorno motor ou mental, autismo ou superdotado. Ele é a base a partir da qual a equipe constrói ações motrizes para o desenvolvimento biopsicossocial, tanto terapêuticos, educacionais e equestres que mobilizem e estimulem o praticante.

Nesse sentido, a equipe exercita a produção coletiva de conhecimentos equoterápicos que, efetivamente, se constroem a partir de um ambiente lúdico de brinquedos, brincadeiras, jogos, música, teatro e autonomia, em uma perspectiva inclusiva, para que o sujeito especial exerça sua interação colaborativa.

O que nos preocupa é revelar o caráter prático e positivo dessa comunicação práxica. Do mesmo modo que se cumprem ações motrizes não opacas, um outro agente (o auxiliar lateral) é introduzido no universo equoterápico para zelar pela segurança do praticante. No decorrer da prática, ele vai colocando em ordem estratégias para amparar o praticante e, com isso, ajusta-se para qualquer emergência incerta no ambiente. O papel do auxiliar lateral é subsidiar as respostas motrizes do praticante que podem ser o conflito motor, o medo e o risco de cair do cavalo.

\footnotetext{
${ }^{4}$ Atividade psicomotriz é visível no encontro motor. Ela inclui o indivíduo atuando só, dentro deste sistema (o encontro motor). Porém, todas as condutas motrizes próprias do indivíduo devem ser guiadas por uma dada estrutura motriz já formulada e convencionalmente aceita pelo contrato ludomotor. A atividade pisicomotriz concebe que o ato psicomotriz faz parte das ações comuns do sistema. Porém, nem por isso deixa de ser constituída de variações motrizes. Por isso, a psicomotricidade do sujeito praticante tem que ser codificada, com um nível de observação, subjetivamente comprovável dentro do sistema. Isso indica como o indivíduo se expõe significativamente em atos motrizes distintos, preservando os aspectos comuns das normas e do funcionamento do encontro motor equoterápico (RAMOS, 2007).
} 
O risco de cair do cavalo pode levar toda a equipe a antecipar uma tomada de decisão imprevista, via a cooperação de ações, dentro do próprio grupo. Isso se dá por meio de acordos internos entre ações de cada agente, em que cada ato motriz é socializado, atravessadamente, de signos (motrizes), que são pistas de uma leitura do ambiente de forma antecipatória. Esta leitura está presente na estrutura, que é feita descobrindo e observando o todo de cada sessão em particular.

Dentro de uma sessão, é fundamental considerar o agente que conduz o cavalo: o auxiliar guia. É importante que este agente seja capaz de conter e/ou dar conta de problemas nas condutas motrizes presumíeis e impresumíveis do cavalo. A sua função, além de atuar na orientação do cavalo, é aguçar seu olhar, escuta e percepção, para que se possam antecipar motoramente as atitudes do cavalo, apreender o que ele expressa e como virá a se expressar.

O modo como o auxiliar guia capta as condutas do cavalo e se posiciona frente a elas, dentro da sessão equoterápica, é relevante. É ele que captura a realidade motriz do cavalo para conduzi-lo de acordo com as necessidades biopsicossociais do praticante no processo terapêutico, educacional ou equestre. É o auxiliar guia que, fundamentado nesse campo grupal, motiva as ações motrizes de 'sujeição' do cavalo ao projeto equoterápico em curso, mediante as quais a equipe constitui uma prática motriz sem sobressaltos, medos ou sustos.

É dessa forma, com o modo peculiar de conduzir o cavalo acoplado à equipe, que recusamos as incertezas e as dúvidas do meio social e, assim, mergulhamos no universo equoterápico confiante. Embora o cavalo tenha condutas características de sua aptidão inata instintiva, existem outros fatores ambientais, como barulhos, objetos externos (quiçá) desconhecidos pelo cavalo, que precisam ser controlados permanentemente durante a sessão.

Ao pensarmos sobre as relações da Praxiologia Motriz e a Equoterapia, percebe-se cada vez mais visivelmente o papel do cavalo dentro da sessão. 0 cavalo, de acordo com a tradição equestre, se assenta na posição daquele agente que gera a ação motriz fundamental da Equoterapia e tem a tarefa de transmissor dessa ação aos praticantes. A ação motriz do cavalo prevalece e confere o significado característico da Equoterapia.

Do cavalo espera-se, ou somos levados a esperar, que ele compartilhe com todos e comporte-se bem. Ele deve atender aos comandos da equipe, cooperar com todos os agentes e refletir a ação motriz tridimensional. Porém, o exercício equoterápico nos ensina que cada cavalo é um cavalo, único e indivisível, que reage de modo individualizado ao que vive dentro e fora desse universo.

A forma como somos levados a compreender o animal (cavalo) e o seu comportamento indivisível vem nos mostrando que ele é um agente ativo. Ele dá 
significado às informações, gestos e ações, avaliando a partir do seu aprendizado na prática equoterápica. A prática tem um referencial de regularidade de treino, memorização, repetição, em uma relação solidária de responder e negar qualquer efeito sinistro dentro de uma sessão.

\section{Quadro 1 - Exposição dos campos de ação para cada papel na Equoterapia}

\begin{tabular}{|c|c|c|c|c|}
\hline$\frac{c}{\text { PAPEL }}$ & PRATICANTE & MEDIADOR & $\begin{array}{l}\text { AUXILIAR } \\
\text { LATERAL }\end{array}$ & AUXILIAR GUIA \\
\hline $\begin{array}{l}\text { INTERAÇÃO } \\
\text { MOTRIZ } \\
\text { COM } \\
\text { O GRUPO }\end{array}$ & $\begin{array}{l}\text { Sujeito que se } \\
\text { ajusta } \\
\text { ativamente à } \\
\text { ação motriz } \\
\text { tridimensional } \\
\text { do cavalo; } \\
\text { Busca o } \\
\text { equilíbrio motriz } \\
\text { regularmente } \\
\text { com a ação } \\
\text { motriz gerada } \\
\text { pelo cavalo; } \\
\text { Seu ajuste } \\
\text { motriz vai sendo } \\
\text { expresso e } \\
\text { compreendido } \\
\text { pelo grupo }\end{array}$ & $\begin{array}{l}\text { Busca a interação } \\
\text { motriz solidária com } \\
\text { todos os agentes } \\
\text { equoterápicos; } \\
\text { Capacidade de } \\
\text { convencimento de } \\
\text { solidariedade no } \\
\text { sentido de construir } \\
\text { atividades } \\
\text { cooperativas em } \\
\text { todo o curso da } \\
\text { sessão equoterápica. }\end{array}$ & $\begin{array}{c}\text { Acompanhar o } \\
\text { praticante } \\
\text { contribuindo para } \\
\text { a sua sustentação } \\
\text { e amparo durante } \\
\text { a sessão } \\
\text { equoterápica; } \\
\text { Coerência motriz } \\
\text { entre as tarefas } \\
\text { trabalhadas pela } \\
\text { equipe no seu } \\
\text { curso específico e } \\
\text { projeto global de } \\
\text { assistência ao } \\
\text { praticante. }\end{array}$ & $\begin{array}{c}\text { Ele deve aguçar } \\
\text { seu olhar ao todo } \\
\text { no campo } \\
\text { equoterápico; } \\
\text { Escutar e perceber } \\
\text { fatores externos } \\
\text { para que se } \\
\text { possam antecipar } \\
\text { motoramente as } \\
\text { atitudes do } \\
\text { cavalo; } \\
\text { Apreender o que o } \\
\text { cavalo está } \\
\text { expressando e } \\
\text { como ele virá a se } \\
\text { expressar. }\end{array}$ \\
\hline $\begin{array}{c}\text { RELAÇÃO COM A } \\
\text { ESTRUTURA } \\
\text { EQUOTERÁPICA }\end{array}$ & $\begin{array}{l}\text { Cumprir todas } \\
\text { as tarefas } \\
\text { motrizes } \\
\text { acordadas pelo } \\
\text { grupo }\end{array}$ & $\begin{array}{l}\text { Planejar o evento } \\
\text { equoterápico; } \\
\text { Responsabilidade de } \\
\text { mediar a sessão } \\
\text { equoterápica; } \\
\text { Organizador de todas } \\
\text { as tarefas; } \\
\text { Desenvoltura no uso } \\
\text { da linguagem oral; } \\
\text { Transmitir o plano } \\
\text { terapêutico a todos } \\
\text { dentro da sessão } \\
\text { equoterápica. }\end{array}$ & $\begin{array}{c}\text { Seu papel } \\
\text { fundamental é } \\
\text { cuidar da } \\
\text { segurança do } \\
\text { praticante. }\end{array}$ & $\begin{array}{l}\text { Função de conter } \\
\text { e/ou dar conta de } \\
\text { problemas nos } \\
\text { procedimentos } \\
\text { motrizes } \\
\text { presumíveis e } \\
\text { impresumíveis do } \\
\text { cavalo. }\end{array}$ \\
\hline $\begin{array}{l}\text { RELAÇÃO COM O } \\
\text { CAVALO }\end{array}$ & $\begin{array}{l}\text { Colaboração e } \\
\text { vínculo } \\
\text { sociomotriz com } \\
\text { o cavalo e os } \\
\text { agentes } \\
\text { equoterápicos }\end{array}$ & $\begin{array}{c}\text { Clareza de ordens e } \\
\text { sinais no sentido de } \\
\text { que facilitem as } \\
\text { ações motrizes para } \\
\text { o cavalo cumprir sua } \\
\text { função; } \\
\text { Clareza motriz de } \\
\text { solidariedade com o } \\
\text { cavalo. }\end{array}$ & $\begin{array}{c}\text { Articulação de } \\
\text { solidariedade } \\
\text { entre as ações } \\
\text { motrizes } \\
\text { desenvolvidas } \\
\text { pelo cavalo, } \\
\text { articuladas com o } \\
\text { praticante sobre o } \\
\text { cavalo. }\end{array}$ & $\begin{array}{c}\text { O agente que } \\
\text { conduz o cavalo } \\
\text { dentro de uma } \\
\text { sessão } \\
\text { equoterápica e } \\
\text { resolve qualquer } \\
\text { problema com o } \\
\text { cavalo. }\end{array}$ \\
\hline
\end{tabular}




\section{A SEMÂNTICA INTERNA DO SISTEMA PRAXIOLÓGICO DA EQUOTERAPIA}

Na Equoterapia, a valorização positiva da comunicação motriz merece destaque. O cuidado com o praticante sobre o cavalo expressa ações motrizes colaborativas. A presença viva da solidariedade, em todas as ações, revela a força de situações de diálogos da equipe equoterápica em uma rede de interação, que marca a colaboração de todo o grupo, expressando a totalidade de intimidade entre humanos e cavalos.

Essa solidariedade mostra um sistema sem competição. Em todas as situações aparece uma produção semiológica, rica em leituras da situação motriz, em particular. O foco do resultado está em não negar o processo interativo e em mitigar as incertezas. A ação psicomotriz oscilante do praticante sobre o cavalo é movida cooperativamente. Em cada ato motriz do praticante, os agentes devem se organizar ativamente, interpretando as mensagens corpóreas dele e da equipe, ganhando exclusivamente a vitalidade nas trocas motrizes.

A práxis equoterápica traz o conceito de gestemas, ou seja, a classe de atitudes, gestos, mímicas e comportamentos motrizes que indicam um sinal relacional, com substituição da palavra (PARLEBAS, 1999). Compreender um gestema, como estalo dos lábios (beijinhos) para o cavalo começar a sessão, é ter a sensibilidade de decodificar um signo convencional necessário nesse universo. 0 "beijinho" para começar a sessão equoterápica é, dentro do olhar da semiologia motriz, uma unidade mínima de comunicação que aborda as parcerias dos agentes que se achegam coletivamente para se apropriarem de uma melhor comunicação do todo.

A semântica equoterápica reconhece esse e outros significados práxicos que dependem do contexto entre humanos e cavalo. Isso, na atividade da Equoterapia, baseia-se no que o "leitor" localiza nessa superfície motriz. Admitimos que a semântica equestre se ocupa dos significados explícitos de um tipo de conduta motriz do cavalo ou humana, em que o significante é comportamento motriz observável e cujo significado é o projeto tático (a meta desejada) correspondente, tal como o comportamento é compreendido (PARLEBAS, 1987). Esses signos motrizes são considerados praxemas, que, devem ser unidades comportamentais mais próximas da convenção equoterápica.

Apreciar esse contexto radiográfico é precisamente o que serve para distinguir a ciência da Praxiologia Motriz. Segundo Lagardera Otero e Lavega Burgués (2003, p. 191), a ciência em questão se dedicaria a explicar os indícios que anunciam papéis sociomotrizes imanentes, desempenhando um cenário de interpretação do sistema motriz em jogo. Supõe-se, nesse sentido que todos os agentes devem desenvolver um conjunto de mensagens corpóreas com significação comunicativa, revestida de solidariedade. 
Esses papéis sociomotrizes representam uma comunicação direta dentro de um conjunto de mensagens motrizes para o arranjo da equipe, pois quando se percebe qualquer alteração do cavalo e/ou do praticante, o mediador faz uso da fala (linguagem verbal) e dá o comando: "Passa a perna". O auxiliar guia freia o cavalo; o auxiliar lateral imediatamente retira o pé do praticante do estribo, flexiona a perna do praticante e o move para o lado do mediador; e o mediador abraça o quadril do praticante e o retira de cima do cavalo.

Como se pode depreender dessa prática, a semântica ocupa-se do sentido de que é dependente nesse contexto motor, da situação; ela se dedica ao que está explícito na superfície motriz, tácita e ao que a equipe identifica nos indícios motrizes do grupo. Para tanto, o grupo tem que conhecer o conjunto de ações implícitas no mundo equoterápico, por meio de tomadas de decisões cooperativas, que confirmem a claridade de condutas motrizes dialógicas, nas trocas colaborativas entre os agentes, como nos mostra o texto de Lagardera Otero e Lavega Burgués (2003, p.192):

Estamos ante a um conflito entre a seguridade e a rapidez da decisão estratégica; entre a precipitação e a antecipação... Cada jogador [agente equoterápico], em função de sua capacidade para ler os demais, se fixará na posição de apoios, a orientação dos segmentos corporais, na orientação do comando, nas trocas de direção, de aceleração, no modo de ocupar o espaço... para intervir em ótimas condições.

Vale ressaltar que essa semântica depende da lógica interna da situação motriz, subtendida ao domínio comum da práxis sistêmica, do diálogo corpóreo, com o objetivo de observar a cumplicidade fundamental que liga todo da estrutura, em que os participantes devem se comunicar todo o tempo, pois a Equoterapia pode ter o imprevisto. A incerteza é o motivo do pensamento de uma realidade que pode vir a existir se a práxis não for devidamente dialógica.

A suspeição do conflito motor, por sua vez, é um tipo de dedução calcada não só na falta da comunicação interna do sistema, mas também na realidade externa. Normalmente, a Equoterapia considera o meio externo, o qual pode trazer conflitos. Eles nos revelam o papel vigilante dos agentes, os quais devem buscar respostas que não afetem a cooperação dentro de uma sessão, como por exemplo, se um cavalo se alterar com o voo de uma borboleta que passa no ambiente externo. Provavelmente, a sessão passa por uma atividade perigosa, que implicará ações para conter o cavalo e retirada do praticante. Emerge o papel cooperativo do grupo na atividade de dar total segurança para o praticante.

O espectro instintivo do cavalo se pauta dentro dessa lógica interna da Equoterapia. Na lógica interna dela, pode embrenhar-se o perigo dentro de uma sessão. É preciso realizar toda composição de segurança para o praticante que oscila sobre o cavalo. Também é preciso ter informações do meio externo para 
saber que ele (o meio) pode realizar uma inferência que não permita atribuir sentido ao que foi planejado para a sessão, considerando a informação contraditória e que não corresponde ao que foi sistematicamente organizado.

\section{APEAR TRANSITORIAMENTE NO CURSO CONTÍNUO DA PRAXIOLOGIA MOTRIZ}

Apear sinaliza que a sessão equoterápica temporariamente se completou. A tarefa foi apresentar a proposta de a Equoterapia ser radiografada pela Praxiologia Motriz. Esta ajustou-se à possibilidade de mostrar como se efetiva o processo interativo de uma práxis motriz da UFRRJ. O processo interativo é sempre compartilhado entre os agentes, em que cada um apresenta sua possiblidade solidária. Esse processo vivido na Equoterapia da UFRRJ, seguramente, é também vivenciado em outras Equoterapias, que, com certeza têm princípios comuns, como eixos norteadores na construção das diversas atividades que essa prática exige.

Todas as situações motrizes, como: jogos, brincadeiras e danças, evidenciam a existência desses universais ludomotrizes, que podem muito bem ser percebidos. É óbvio que esses universais trazem contribuições que enriquecem a análise que o agente pesquisador pode fazer no cotidiano do seu trabalho. Esse trabalho revelou a lógica interna vivida pelos que vivenciam a Equoterapia da UFRRJ, destacando muitos aspectos que podem ser compreendidos e/ou valorizados na profundidade do sistema motor.

A Praxiologia Motriz tem uma função relevante nas possibilidades descritivas e de análise de um fenômeno motor como a Equoterapia. Descrevemos e analisamos este fenômeno dentro de um âmbito intraestrutural. Essas possibilidades afetam muitas outras questões, que podem afetar outras respostas. O pensamento praxiológico, ao falar da dinâmica de desvelar uma dada situação motriz, é bastante ilustrativo neste modo operatório de observar/descrever/analisar/explicar.

O exemplo praxiológico para explicar a concepção de estrutura do jogo está relacionado com a teoria musical. As músicas podem ser apropriadas por um leigo por sua beleza sonora, assim como poderão ser desveladas suas sequências, interesse maior dos músicos e estudiosos desse campo. (RIBAS, 2014, p. 537)

O pensamento praxiológico sinaliza o descobrimento interno de um fenômeno motor, com um olhar mais apurado sobre o que se constrói no cotidiano de um encontro motor dado pelos que jogam, brincam, dançam e montam. Produzir o diálogo com a ciência praxiológica é uma tarefa educativa e permite que outros contextos possam ser lidos, proporcionando reflexões, inquietações e debates sobre cada encontro motor dentro de sua natureza semiológica e sociocultural. 


\section{REFERÊNCIAS}

ANDE, Associação Nacional de Equoterapia. Curso básico de Equoterapia. Brasília: DF, 2013. Disponível em: http://equoterapia.org.br/articles/index/articles list/134/80/0

CRUZ, F. Q. F. Equoterapia educacional: um aporte colaborativo na inclusão da criança com transtorno do espectro autista na escola - 119 f. Dissertação (Mestrado em Educação Agrícola) - Instituto de Agronomia, Universidade Federal Rural do Rio de Janeiro, Seropédica, RJ, 2016.

GRANJA, U.S.O. Conflicto y Educación Física a luz da praxiología motriz: Estudio de caso de un centro educativo primaria. Tesis Doctoral. Lleida, 2011.

HERNANDEZ MORENO, J. La praxiología motriz, ciEncia de la acción motriz? In: Apunts Educación Física y Deportes. Catalunya: Institut Nacional d’Educación Física, 1993.

LAGARDERA OTERO, F.; LAVEGA BURGUÉS, P. Introdución a la Praxiologia Motriz. Barcelona: Editorial Paidotribo, 2003.

PARLEBAS, P. Perspectivas para una educacion fisica moderna. Andalucia: Andalucia, Unisport, 1987.

PARLEBAS, P. Los universais de los juegos desportivos. In: Revista de Praxiologia Motriz. Las Palmas de Gran Canária. n. 0, v. 1, p. 15-30, 1996.

PARLEBAS, P. Jeux, Sports et sociétés: lexique de la praxiologie motrice. Paris: Institut du sport et de l'education physique, 1999.

RAMOS, J. R. S. A semiologia e a educação física: um diálogo com Betti e Parlebas. Revista Brasileira Ciência do Esporte. Campinas v. 2, n. 21, p118-121, 2000.

RAMOS, J. R. S. O jogo como linguagem: a abordagem funcionalista da linguagem nas práticas corporais coletivas. (Doutorado em Estudos da Linguagem). Niterói: Universidade Federal Fluminense, 2007. $190 f$.

RAMOS, J. R. S. Praxiologia Motriz e Equoterapia: uma radiografia praxiológica da lógica interna das mediações equoterápicas dentro da escola. In: RIBAS, J. F. M. Praxiologia Motriz na América Latina. Aportes para a Didática na Educação Física. Ijuí: Ed. Unijuí, 2017. p.177-197.

RIBAS, J. F. M. Praxiologia Motriz. In: Dicionário crítico da educação física. GONZÁLEZ, F. J. FENSTERSEIFER. P. E. 3. ed. ver. e ampl. Ijui: Ed. Unijuí, 2014. p. 535-538. 